\title{
0 brinquedo terapêutico e 0 impacto na hospitalização da criança: revisão de escopo
}

Therapeutic play and the impact on hospitalization of children: scoping review Juego terapéutico y el impacto en la hospitalización de niños: revisión del alcance

Crislaine Siqueira de Sousa ${ }^{1}$ (1D nttps://orcid.org/0000-0001-6200-1568

Beatriz da Costa Barreto ${ }^{1}$ (1) https://orid.org/0000-0002-6805-7148

Giovanna Angélica Sousa Santana ${ }^{1}$ (1) https:// orcid.org/0000-0002-5565-0057

Júlia Vieira Ferreira Miguel ${ }^{1}$ (1) https://orcid.org/0000-0003-4740-4718

Lucas de Souza Braz ${ }^{1}$ (D) https://orcid.org/0000-0002-1854-6592

Luana Nunes Lima ${ }^{1}$ (ID htps://orcid.org/0000-0003-4620-9400

Manuela Costa Melo ${ }^{1}$ (D) htps://orcid.org/0000-0002-2018-1801

\section{Resumo}

Objetivo: Identificar publicações científicas acerca do impacto do uso do brinquedo terapêutico e o brincar na unidade pediátrica.

Métodos: Revisão de escopo realizada em novembro de 2019, mediante as recomendações do The Institute Joanna Briggs. Foram selecionados 13 estudos e apresentados no diagrama de fluxo Preferred Reporting Items for Systematic Reviews and MetaAnalyses.

Resultados: Identificou-se que o brinquedo terapêutico e o brincar possuem impacto positivo na hospitalização da criança. Os estudos identificados foram divididos em três categorias: o brinquedo terapêutico e o brincar na percepção das crianças, pais/acompanhantes e equipe multiprofissional.

Conclusão: Identificaram-se publicações científicas que apresentaram o brinquedo terapêutico e o brincar como ferramentas facilitadoras do cuidado às crianças internadas em unidades pediátricas.

\section{Abstract}

Objective: To identify scientific publications on the impact of the use of therapeutic toys and playing in the pediatric unit.

Methods: Scoping review conducted in November 2019, through the recommendations of The Institute Joanna Briggs. 13 studies were selected and presented in the flow chart Preferred Reporting Items for Systematic Reviews and MetaAnalyses.

Results: It was identified that therapeutic toy and play have a positive impact on the child's hospitalization. The studies identified were divided into three categories: the therapeutic toy and play in the perception of children, parents/companions and multiprofessional team.

Conclusion: Scientific publications were identified that presented therapeutic toys and play as tools that facilitate the care of children hospitalized in pediatric units.

\section{Resumen}

Objetivo: Identificar publicaciones científicas sobre el impacto del uso de juguetes terapéuticos y el juego en la unidad pediátrica.

Métodos: Examen del alcance realizado en noviembre de 2019, mediante las recomendaciones del Instituto Joanna Briggs. Se seleccionaron 13 estudios que se presentaron en el diagrama de flujo Preferred Reporting Items for Systematic Reviews and MetaAnalyses.

Resultados: Se identificó que el juguete terapéutico y el juego tienen un impacto positivo en la hospitalización del niño. Los estudios identificados se dividieron en tres categorías: el juguete terapéutico y el juego en la percepción de los niños, los padres/acompañantes y el equipo multiprofesional.

Conclusión: Se identificaron publicaciones científicas que presentaban juguetes terapéuticos y jugaban como herramientas que facilitan la atención de los niños hospitalizados en unidades pediátricas.

\section{Como citar:}

Sousa CS, Barreto BC, Santana GA, Miguel JV, Braz LS, Lima LN, et al. 0 brinquedo terapêutico e o impacto na hospitalização da criança: revisão de escopo. Rev Soc Bras Enferm Ped. 2021;21(2):173-80.

${ }^{1}$ Escola Superior em Ciências da Saúde, Brasília, DF, Brasil.

Conflitos de interesse: nada a declarar.

Submetido: 30 de Março de 2020 | Aceito: 3 de Dezembro de 2021

Autor correspondente: Luana Nunes Lima | E-mail: Iuananlima@gmail.com

Dol: http://dx.doi.org/10.31508/1676-379320210024 


\section{Introdução}

O brincar é uma importante ferramenta para o desenvolvimento saudável da criança, sendo também uma necessidade básica natural da infância. ${ }^{(1)}$ No contexto do Brasil, essa necessidade é reconhecida também como um direito. $\mathrm{O}$ Estatuto da Criança e do Adolescente (ECA), no art. 16, reconhece o "brincar, praticar esportes e divertir-se" como um direito de liberdade.(2) Entretanto, quando a criança adoece e é submetida à hospitalização, esse direito, tal como o hábito de brincar, é ameaçado. Isso acontece porque o processo de hospitalização traz consigo mudanças na rotina diária da criança, afastando-a cada vez mais de atividades lúdicas e recreativas e exigindo uma adaptação forçada e imediata a uma nova realidade distante da habitual. ${ }^{(3-5)} \mathrm{E}$ também os tratamentos hospitalares vêm acompanhados de procedimentos invasivos e dolorosos que provocam medo na criança e podem gerar um possível trauma, perdurando até mesmo após a alta hospitalar. ${ }^{(6)}$

Dessa forma, a fim de reduzir o impacto causado pela hospitalização e pelo sofrimento que decorre desse processo, o brincar e o brinquedo terapêutico (BT) tornam-se valiosas ferramentas de intervenção nesse âmbito. O BT se classifica em três diferentes tipos: o instrucional, o dramático e o capacitador de funções fisiológicas. ${ }^{(6)}$

No contexto terapêutico das crianças em regime de internação, o brincar oferece uma realidade alternativa e torna-se estratégia de enfrentamento ao estresse, contribuindo para a interação das crianças e dos seus acompanhantes com os profissionais de saúde, possibilitando a comunicação efetiva e a troca de informações, que possui como consequência a tomada de decisões mais consciente e humanizada focada nas particularidades de cada criança. Ao compreender a doença e seus respectivos procedimentos, a criança adere, participa e coopera com o tratamento, minimizando-se o medo e o sofrimento imposto pelo desconhecido. ${ }^{(5-9)}$

Considera-se que as internações hospitalares sejam capazes de alterar a interação da criança com o meio, portanto o presente estudo foi motivado pelo que o brincar e o BT representam, pois essas ferramentas são amplamente reconhecidas como facilitadoras da comunicação entre o profissional de saúde e a criança, pois elas favorecem a assistência humanizada e holística, e reduzem os efeitos traumáticos e dolorosos da internação. Esses aspectos são evidenciados pelos estudos nacionais e internacionais que tratam da internação da criança, porém, apesar de a literatura reconhecer a influência e os benefícios psíquicos dessas duas ferramentas, faz-se necessário identificar estudos que expressam seu impacto diante da hospitalização, da realização de procedimentos e da coleta de amostra de material para exames, entre outras situações inerentes à criança que é afastada do seu convívio familiar.

Assim, este estudo possui o objetivo de identificar publicações científicas acerca do impacto do uso do BT e o brincar na unidade pediátrica.

\section{Métodos}

\section{Desenho e local do estudo}

Trata-se de uma revisão de escopo, que consiste em uma revisão exploratória e sistematizada que permite ser conduzida de forma a identificar lacunas e mapear estudos relevantes em determinada área. ${ }^{(10)} \mathrm{O}$ protocolo metodológico do estudo, The Joanna Briggs Institute for Scoping Reviews, permitiu esclarecer evidências e estabeleceu a aplicação da estratégia PCC, acrônimo para: População $(\mathrm{P})$ - crianças internadas e seus familiares e equipe multiprofissional; Conceito (C) - impacto do uso do BT; e Contexto (C) - unidade pediátrica, para a construção da pergunta de pesquisa. ${ }^{(11,12)}$ Dessa maneira, identifica-se a questão de revisão: “O que diz a literatura científica acerca do impacto do uso do brinquedo terapêutico e o brincar na unidade pediátrica?".

\section{Amostra e critérios de inclusão dos estudos}

Foram estabelecidos os critérios de inclusão (estudos publicados nos últimos cinco anos, nos idiomas inglês e português, que analisaram a importância do brincar no contexto da hospitalização infantil) e os de exclusão (editoriais, cartas ao editor, comentários críticos e livros abordando o assunto, assim como duplicatas e artigos não disponíveis na íntegra). 


\section{Busca em base de dados}

Foi realizada busca na Biblioteca Virtual em Saúde, por meio dos descritores do Medical Subject Headings (MeSH). O limite temporal foi de 2015 a 2019. Foram utilizados os descritores "Play" AND "Playthings", "Children" e "Hospitalization". Para conexão dos descritores, utilizou-se o operador booleano: $A N D$. Esse limite temporal foi escolhido por buscar as atualizações no decorrer dos cinco últimos anos.

\section{Extração e categoria dos resultados}

Para a elegibilidade dos estudos, estes foram identificados com base nos critérios de inclusão e exclusão preestabelecidos. No primeiro momento, foram realizadas leituras exploratórias de títulos e resumos, para pré-selecionar aqueles que respondessem à questão da revisão ou excluir os que não se encaixavam nos critérios; e no segundo momento, procedeu-se à leitura na íntegra dos elegíveis. Os estudos selecionados foram caracterizados nas variáveis: ano, objetivo do estudo, população/amostra e tipo/ desenho de estudo. Esse processo de extração seguiu a recomendação do Joanna Briggs Institute (JBI), ${ }^{(11)} \mathrm{e}$ as variáveis foram apresentadas em um fluxograma. O processo de busca e seleção do material pode ser visto na figura 1.

Para estabelecer as categorias temáticas, foram seguidos os aspectos de acordo com o acrônimo PCC identificado, ou seja, "crianças internadas, seus familiares e equipe multiprofissional", "impacto do uso brinquedo terapêutico" e "unidade pediátrica". Dessa maneira, os estudos foram identificados em três categorias: O brinquedo terapêutico e o brincar na percepção das crianças; $\mathrm{O}$ brinquedo terapêutico e o brincar na percepção pais/acompanhantes; e O brinquedo terapêutico e o brincar na percepção da equipe multidisciplinar. As categorias temáticas foram interpretadas com base na literatura.

No intuito de seguir o rigor metodológico, a seleção e a extração dos estudos foram realizadas por três revisores de forma independente, para, assim, reduzir prováveis erros ou vieses de avaliação e interpretação dos resultados e garantir a fidedignidade dos resultados. Nos casos em que ocorreram desacordos, houve discussão entre dois outros avaliadores e análise pelo sexto e sétimo avaliador, com o intuito de alcançar consenso.

A figura 1 exibe o processo de seleção dos artigos, com os artigos incluídos, excluídos e o resultado final.

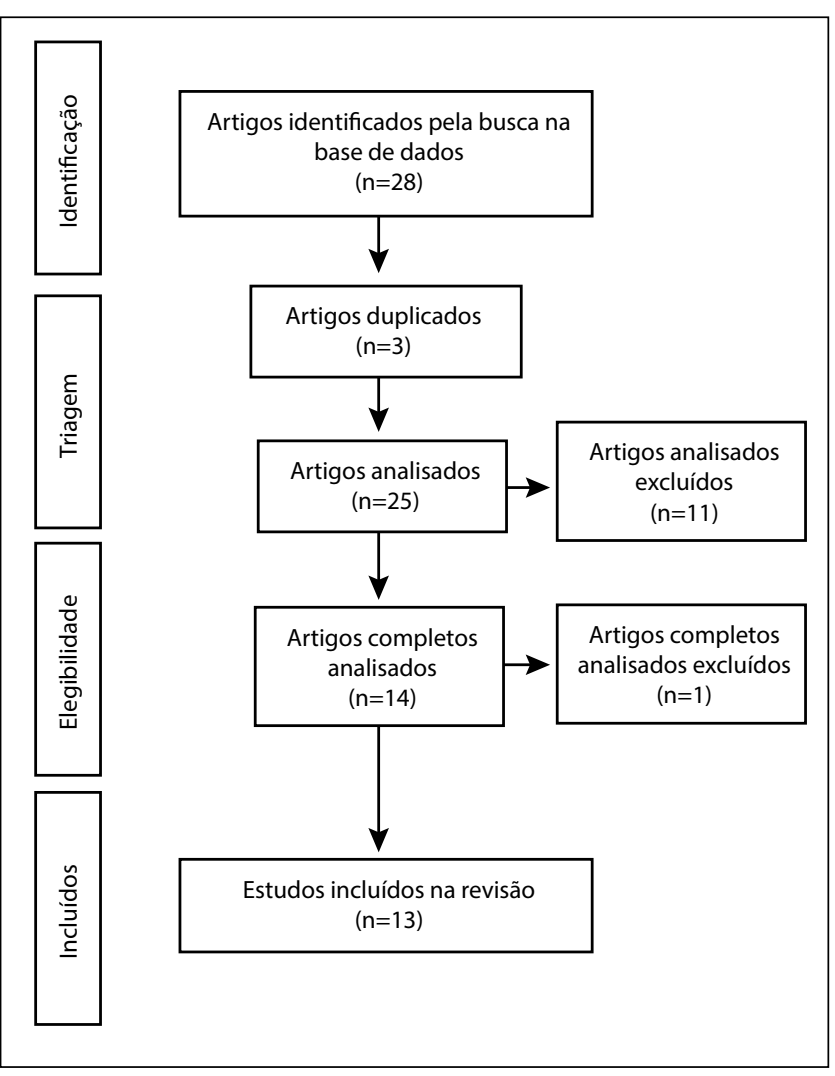

Figura 1. Seleção dos estudos nas bases de dados pesquisadas

\section{Resultados}

Foram selecionados 13 artigos, numerados de 1 a 13 para a composição dos quadros a seguir. Todos foram publicados entre os anos de 2015 e 2018. O quadro 1 apresenta o ano da publicação, objetivo do estudo, população/amostra e tipo do estudo. A abordagem qualitativa de caráter exploratório-descritivo foi adotada em $50 \%$ dos artigos, a pesquisa quantitativa de caráter exploratório-descritivo, em 8,33\%, o estudo analítico exploratório de abordagem quantitativa, em 8,33\%, a revisão integrativa de literatura, em $16,67 \%$, a revisão sistemática, em $8,33 \%$, e a intervenção não controlada com variáveis quantitativas, em $8,33 \%$.

O quadro 2 expressa os principais resultados encontrados na literatura acerca do impacto do uso do 
Quadro 1. Distribuição dos estudos incluídos de acordo com a identificação do ano de publicação, objetivo do estudo, população, desenho do estudo e principais resultados

\begin{tabular}{|c|c|c|c|}
\hline Ano & Objetivo do estudo & População/amostra & Desenho do estudo \\
\hline $2017^{(1)}$ & $\begin{array}{l}\text { Descrever o comportamento infantil, com o uso do } \\
\text { brinquedo terapêutico, em uma unidade de terapia } \\
\text { intensiva pediátrica }\end{array}$ & $\begin{array}{l}11 \text { pacientes internados na unidade de terapia intensiva } \\
\text { pediátrica }\end{array}$ & Abordagem quantitativa \\
\hline $2018^{(2)}$ & Sistematizar o brincar da criança com câncer & $\begin{array}{l}22 \text { estudos que incluíram como participantes crianças, } \\
\text { pais e profissionais de enfermagem }\end{array}$ & Revisão sistemática \\
\hline $2015^{(3)}$ & $\begin{array}{l}\text { Analisar a opinião dos acompanhantes sobre a } \\
\text { promoção do brincar no espaço de hospitalização } \\
\text { da criança }\end{array}$ & 65 mães de crianças internadas & Abordagem qualitativa \\
\hline $2018^{(4)}$ & $\begin{array}{l}\text { Identificar a percepção dos acompanhantes das } \\
\text { crianças hospitalizadas com relação às atividades } \\
\text { lúdicas }\end{array}$ & 10 acompanhantes de crianças internadas & Abordagem qualitativa \\
\hline $2016^{(5)}$ & $\begin{array}{l}\text { Analisar o uso do brincar na assistência à criança } \\
\text { hospitalizada na perspectiva dos pais }\end{array}$ & $\begin{array}{l}13 \text { pais/acompanhantes de crianças hospitalizadas na } \\
\text { unidade pediátrica }\end{array}$ & Abordagem qualitativa \\
\hline $2016^{(6)}$ & $\begin{array}{l}\text { Comparar as reações manifestadas pela criança } \\
\text { diante do preparo para punção venosa antes e após } \\
\text { o uso do BTI }\end{array}$ & 21 crianças hospitalizadas, pré-escolares e escolares & $\begin{array}{l}\text { Pesquisa analítica, exploratória e de } \\
\text { abordagem quantitativa }\end{array}$ \\
\hline $2017^{(7)}$ & $\begin{array}{l}\text { Conhecer a percepção dos pais quanto à inserção } \\
\text { de atividades lúdicas durante a internação hospitalar } \\
\text { da criança }\end{array}$ & $\begin{array}{l}\text { Seis pais de crianças com faixa etária de } 5 \text { a } 10 \text { anos, } \\
\text { internadas na pediatria }\end{array}$ & Pesquisa qualitativa \\
\hline $2018^{(8)}$ & $\begin{array}{l}\text { Elucidar a experiência da equipe multidisciplinar } \\
\text { com o uso do brinquedo durante o tratamento de } \\
\text { crianças com câncer }\end{array}$ & Dez membros da equipe multidisciplinar & Abordagem qualitativa \\
\hline $2018^{(9)}$ & $\begin{array}{l}\text { Compreender o brincar como estratégia para } \\
\text { enfrentamento do } \\
\text { tratamento quimioterápico em crianças }\end{array}$ & $\begin{array}{l}\text { Crianças entre } 7 \text { e } 12 \text { anos de idade que possuíam } \\
\text { diagnóstico de câncer e se encontravam em tratamento } \\
\text { quimioterápico }\end{array}$ & Abordagem qualitativa \\
\hline $2018^{(12)}$ & $\begin{array}{l}\text { Analisar a importância do lúdico no contexto da } \\
\text { hospitalização infantil }\end{array}$ & $\begin{array}{l}10 \text { estudos que incluíram como participantes crianças, } \\
\text { enfermeiros, técnicos de enfermagem, familiares, } \\
\text { médicos, mães e pais/responsáveis }\end{array}$ & $\begin{array}{l}\text { Revisão integrativa da } \\
\text { literatura }\end{array}$ \\
\hline $2018^{(13)}$ & $\begin{array}{l}\text { Compreender o significado do brincar para a criança } \\
\text { hospitalizada em precaução }\end{array}$ & $\begin{array}{l}\text { Oito crianças com idades entre } 5 \text { e } 10 \text { anos internadas } \\
\text { em um hospital público infantil }\end{array}$ & Abordagem qualitativa \\
\hline $2016^{(14)}$ & $\begin{array}{l}\text { Comparar a comunicação não verbal das crianças } \\
\text { antes e durante a interação com palhaços }\end{array}$ & $\begin{array}{l}41 \text { crianças internadas na unidade pediátrica de um } \\
\text { hospital público universitário }\end{array}$ & $\begin{array}{l}\text { Estudo de intervenção não } \\
\text { controlado, transversal, com } \\
\text { abordagem quantitativa } \\
\end{array}$ \\
\hline $2016^{(15)}$ & $\begin{array}{l}\text { Descrever os principais benefícios da promoção do } \\
\text { brincar para a recuperação da criança hospitalizada } \\
\text { e as principais ações de gestão estratégica para sua } \\
\text { efetividade }\end{array}$ & $\begin{array}{l}11 \text { estudos que incluíram crianças, enfermeiros, } \\
\text { médicos, estudantes de Enfermagem, Medicina e } \\
\text { Nutrição }\end{array}$ & Revisão de literatura integrativa \\
\hline
\end{tabular}

BTI - brinquedo terapêutico instrucional; BVS - Biblioteca Virtual em Saúde; MEDLINE: Medical Literature Analysis and Retrieval System Online; LILACS - Literatura Latino-Americana e do Caribe em Ciências da Saúde; BDENF - Base de Dados de Enfermagem; SciELO - Scientific Electronic Library Online; Capes - Coordenação de Aperfeiçoamento de Pessoal de Nível Superior

BT e o brincar na unidade pediátrica. Observou-se que o lúdico, representado pelo brincar e o BT, é demonstrado como um fator de estreitamento dos laços das crianças com os pais/acompanhantes, além de reduzir estressores e facilitar a assistência por parte da equipe multidisciplinar.

\section{Discussão}

\section{O brinquedo terapêutico e o brincar na percepção das crianças}

Brincar é um dos aspectos mais importantes na vida da criança, sendo o meio pelo qual pode inventar e re- inventar coisas no mundo mágico, repleto de fantasia e aventuras, onde não há limites para a imaginação e a criatividade. ${ }^{(1)}$ As crianças representam de forma lúdica suas emoções, medos e ansiedades, criando condições e mecanismos para enfrentar e compreender o processo de hospitalização. Além disso, o brincar para a criança também possibilita a estimulação de suas potencialidades e criatividade, além de promover a interação e a comunicação com o outro e com o mundo. E, quando é inserido dentro do contexto hospitalar, o brincar acaba por exercer também uma função terapêutica, proporcionando melhora do bem-estar físico e emocional. ${ }^{(13)}$

O brincar auxilia a criança no tratamento do câncer e apresenta os seguintes benefícios: melhoria na 
Quadro 2. Distribuição dos estudos com relação aos resultados dos estudos

\begin{tabular}{|c|}
\hline idos \\
\hline $\begin{array}{l}\text { Estudo de abordagem quantitativa que se constituiu na intervenção do BT entre } 11 \text { crianças internadas em UTI pediátrica, sendo descrito o comportamento infantil } \\
\text { de acordo } 17 \text { variáveis observadas e assinaladas pela pesquisadora na sessão lúdica, conforme a ausência ou a presença do comportamento apresentado. A } \\
\text { pesquisadora registrava no instrumento observações e verbalizações do paciente durante a sessão de BT. }{ }^{(1)}\end{array}$ \\
\hline $\begin{array}{l}\text { Estudo de revisão sistemática que evidenciou o brincar como auxiliar na adesão ao tratamento e na socialização da criança e denunciou a falta de espaços físicos } \\
\text { para brincar nos hospitais. A formação profissional é pouco discutida. Estudos são necessários para expandir vivências lúdicas de crianças com câncer.(2) }\end{array}$ \\
\hline $\begin{array}{l}\text { Estudo de abordagem qualitativa realizada com } 65 \text { mães de crianças hospitalizadas, no qual foi analisada a opinião das mães sobre a promoção do brincar durante } \\
\text { a internação dos filhos. Todas afirmaram que frequentar a brinquedoteca auxilia na recuperação, proporciona alívio do sofrimento e acalma e alivia as tensões. E } \\
\text { destacaram a importância da brinquedoteca para amenizar os efeitos da hospitalização e auxiliar no desenvolvimento das crianças. }{ }^{(3)}\end{array}$ \\
\hline $\begin{array}{l}\text { Estudo de abordagem qualitativa realizada com } 10 \text { acompanhantes de crianças hospitalizadas, que procurou identificar a percepção dos acompanhantes das } \\
\text { crianças hospitalizadas com relação às atividades lúdicas. Os autores consideram primordial que os profissionais atuantes na pediatria desenvolvam estratégias para } \\
\text { a utilização do BT, para, assim, melhorar a assistência oferecida e, como contribuição, proporcionar o atendimento humanizado e qualificado na área. }{ }^{(4)}\end{array}$ \\
\hline $\begin{array}{l}\text { Estudo de abordagem qualitativa realizada com } 13 \text { pais, que procurou analisar a utilização do brincar no cuidado à criança hospitalizada na perspectiva dos } \\
\text { pais. Observou-se que o brincar é uma ferramenta valiosa para minimizar o estresse da hospitalização e contribuir para melhor adaptação da criança ao hospital, } \\
\text { trazendo benefícios para a promoção do bem-estar, diversão, redução da dor e socialização durante a hospitalização. E também favorece o cuidado humanizado e } \\
\text { integral e a possibilidade de reduzir os prejuízos no desenvolvimento infantil, ocasionados pela vivência da hospitalização. }{ }^{(5)}\end{array}$ \\
\hline $\begin{array}{l}\text { Estudo de abordagem quantitativa realizada com } 21 \text { crianças hospitalizadas, que procurou comparar as reações manifestadas pelas crianças durante o processo de } \\
\text { punção venosa antes e após o uso do BT. O BT constitui-se relevante intervenção para a enfermagem pediátrica, sendo necessário, para sua aplicação sistematizada, } \\
\text { articular ações que visem a uma maior sensibilização dos órgãos gestores dos serviços de pediatria, maior capacitação dos profissionais envolvidos e melhor } \\
\text { abordagem do ensino do BT nos cursos de graduação de enfermagem. }{ }^{(6)}\end{array}$ \\
\hline 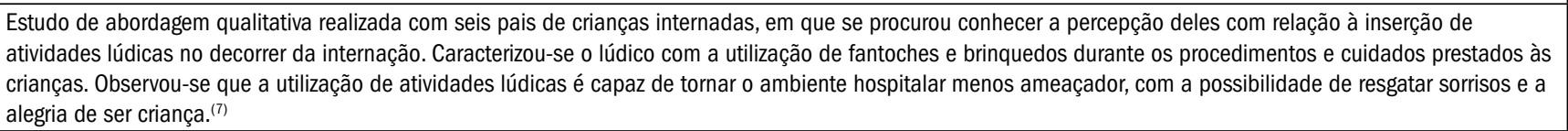 \\
\hline $\begin{array}{l}\text { Estudo de abordagem qualitativa realizada com } 10 \text { membros da equipe multidisciplinar, que procurou elucidar a experiência da equipe com o uso do brinquedo durante } 0 \\
\text { tratamento de crianças com câncer. As experiências compartilhadas revelaram que o brinquedo é uma estratégia fundamental de criação e estreitamento do vínculo com } \\
\text { a criança e sua familia, pois o brincar estabelece a comunicação com a possibilidade da compreensão da criança sobre a sua doença e o tratamento. }{ }^{(8)}\end{array}$ \\
\hline $\begin{array}{l}\text { Estudo de abordagem qualitativa realizada com } 10 \text { crianças entre } 7 \text { e } 12 \text { anos com câncer, em tratamento quimioterápico e hospitalizadas, que procurou } \\
\text { compreender o brincar como estratégia para enfrentamento do tratamento quimioterápico. As crianças compreenderam a relevância do brincar para combater a } \\
\text { ociosidade e destacaram a importância de um espaço lúdico, adaptado às necessidades do tratamento, dentro do ambiente hospitalar. Reforça-se a importância de } \\
\text { investimento, por parte da administração dos hospitais, em espaços e materiais lúdicos e na contratação de pessoal qualificado para facilitar o brincar das crianças } \\
\text { hospitalizadas. }{ }^{(9)}\end{array}$ \\
\hline $\begin{array}{l}\text { Estudo de revisão integrativa em que os estudos evidenciaram que o lúdico possui importância no contexto da hospitalização infantil, uma vez que traz benefícios não } \\
\text { somente para a criança hospitalizada, mas também para a família e a equipe de saúde, além de possibilitar um cuidado humanizado. }{ }^{(12)}\end{array}$ \\
\hline $\begin{array}{l}\text { Estudo de abordagem qualitativa realizada com oito crianças hospitalizadas que procurou compreender o significado do brincar para elas. Foi realizada observação do } \\
\text { participante de atividades lúdicas, mediada pelo comando "desenhar uma criança brincando no quarto do hospital”. } 0 \text { estudo revelou a necessidade de } 0 \text { enfermeiro } \\
\text { usar sua criatividade para buscar estratégias para a criança brincar no decorrer da sua internação. }{ }^{(13)}\end{array}$ \\
\hline $\begin{array}{l}\text { Estudo de abordagem quantitativa com intervenção não controlada realizada com } 41 \text { crianças internadas, que procurou comparar a comunicação não verbal entre as } \\
\text { crianças antes e durante a interação com os palhaços e comparar os seus sinais vitais antes e depois dessa interação. Observou-se que a interação lúdica com os } \\
\text { palhaços pode ser um recurso terapêutico para minimizar os efeitos do ambiente estressante durante a intervenção e melhorar o estado emocional e diminuir a dor } \\
\left.\text { das crianças }{ }^{(14}\right)\end{array}$ \\
\hline tudo de revisão integrativa que evidenciou os principais benefícios da prom \\
\hline
\end{tabular}

BT - brinquedo terapêutico; UTI - unidade de terapia intensiva

qualidade de vida, vivência de momentos de euforia e alegria, redução de irritabilidade, agressividade e ansiedade e aumento de socialização. O aumento de possibilidades de brincar em unidades hospitalares é muito importante. No entanto, o elemento lúdico das atividades propostas, quando visto como um meio de conquistar algo, perde sua essência, deixando de objetivar à vivência livre e emancipadora, característica marcante da ludicidade. ${ }^{(2)}$

Ao brincar, as crianças ressignificam o hospital como um lugar que possibilita a manutenção da saúde, portanto um ambiente apropriado à realização de atividades lúdicas, uma vez que, para elas, ter saúde significa poder brincar, ter energia e fazer as coisas que têm vontade. ${ }^{(13)} \mathrm{E}$ o hospital, mesmo sendo um lugar que costuma ser visto como um contexto de cuidados à doença, também permite que a criança se sociabilize e estabeleça interações, e o poder agir como sujeito criança se faz por intermédio do brincar. Ao brincar, ela subverte as relações de poder advindas dos profissionais de saúde, rompendo a lógica construída de submissão aos adultos, tornando-se, assim, livre de quaisquer amarras. ${ }^{(13)} \mathrm{E}$, com a ludoterapia, a criança passa a aceitar o profissional de saúde que lhe está 
prestando assistência, porque o medo do jaleco branco diminui graças a uma aproximação entre ambos. ${ }^{(12)}$

Além disso, o uso de equipamentos eletrônicos passa a ser ferramenta importante para a ludoterapia, principalmente para crianças que estão impossibilitadas de sair do leito ou com algum equipamento que atrapalhe sua movimentação. (12) Para crianças em quimioterapia, brincar, por meio dos computadores e internet, é importante, porque permite que elas mantenham seus vínculos pessoais e comuniquem-se com pessoas de várias localidades. ${ }^{(9)}$ Essa interação, possibilitada pelo universo virtual, pode auxiliar essas crianças a enfrentar o isolamento e a ociosidade decorrentes da quimioterapia, pois elas permanecem longos períodos em isolamento no hospital, com limitação de movimentos por estarem ligadas à bomba de infusão e pela fadiga, efeito colateral das medicações. ${ }^{(9)}$

Um estudo realizado sobre o uso de BT, em uma unidade de terapia intensiva pediátrica, demonstrou que, durante as sessões do BT, as variáveis "apresenta comportamento verbal e não verbal" evidenciaram sua significância, representando $81,82 \%$ dos comportamentos presentes. Esse comportamento é justificado pelo fato de que o brinquedo atua como efetiva ferramenta de comunicação. As crianças escutam as explicações dos profissionais e, ao mesmo tempo, esclarecem suas dúvidas sobre os procedimentos, assim sendo atenuados os efeitos negativos causados pela hospitalização e proporcionado um ambiente de segurança e conforto. ${ }^{(1)}$

As crianças que, ao se depararem com o cenário lúdico, podiam realizar intervenções nos brinquedos, reproduzindo o que lhes havia sido ensinado, e associavam a semelhança dos brinquedos com a realidade vivenciada no hospital e após a sessão do BT aceitavam melhor o cuidado dos profissionais, estabelecendo interação e propiciando vínculo e confiança. ${ }^{(8)} \mathrm{A}$ interação lúdica das crianças com palhaços é uma estratégia eficaz para redimensionar a energia delas para sentimentos positivos e benéficos. As mudanças comportamentais não verbais durante a intervenção mostram que as crianças ficam mais relaxadas, atenciosas e sorridentes. ${ }^{(14)}$ Além dos efeitos comportamentais e fisiológicos, os benefícios de interagir com palhaços não se restringem a pacientes; família e profissionais também parecem se beneficiar. ${ }^{(14)}$

\section{O brinquedo terapêutico e o brincar na percepção de familiares}

Estudos demonstraram que o brincar pode ser utilizado como estratégia para amenizar o processo de internação da criança na unidade pediátrica, uma vez que são inseridos momentos de diversão, resgatando-se as características infantis. ${ }^{(3,4)}$ Essa abordagem favorece uma melhor adaptação de toda a família durante a hospitalização e um menor desgaste da relação com a criança. Os pais tranquilizam-se e ficam satisfeitos com o contato que a criança passa a ter com atividades de seu cotidiano. ${ }^{(3,4)}$

Um estudo mostrou que os pais e familiares que acompanham a criança acreditam que as atividades de brincar são paliativas diante da situação, pois favorecem a diminuição do estresse, a distração, o esquecimento e o alívio, acalmam e tranquilizam a criança, propiciando relaxamento, diminuição da tensão e consequente melhora de humor e emocional. As atividades, ainda, são descritas como um passatempo, proporcionando momentos de alegria e felicidade à criança, que tem, assim, seu trauma hospitalar amenizado. ${ }^{(3)}$ Pode-se verificar que os familiares são afetados positivamente quando se certificam de que o universo lúdico torna as crianças novamente ativas, espontâneas, ajudando-as a sair da passividade gerada pela doença. ${ }^{(3)}$

As mães sentem-se mais calmas ao perceberem a utilização do brincar com seus filhos, os quais expressam sinais de distração, alegria e superação quanto à hospitalização, pois, enquanto brincam, as crianças se distraem e parecem se esquecer do ambiente em que estão. ${ }^{(5)} \mathrm{O}$ espaço estruturado para o brincar, nesse contexto, a brinquedoteca, favorece a interação livre, fortalecendo o vínculo entre pais e crianças, e os pais, no contexto hospitalar, relacionam-se com seus filhos sem focar apenas a perspectiva da doença. ${ }^{(3)} \mathrm{A}$ criança passa a ter um ambiente próprio, adequado, onde é possível continuar sendo criança e usufruir de atividades indispensáveis para o seu desenvolvimento. ${ }^{(3)}$

O lúdico é uma ferramenta para criar uma nova realidade, onde as crianças repetem, por meio de brincadeiras, momentos dolorosos advindos de procedimentos e da própria internação.(7) Durante a brincadeira, ao assumirem o papel do médico e enfermeiro, as crianças dão injeção em sua boneca, repetindo as 
palavras: "não vai doer". Assim, com a repetição da situação, há um fortalecimento em termos de idealização, criando-se, por meio de seu mundo imaginário, uma nova situação. ${ }^{(7)}$

\section{0 brinquedo terapêutico e o brincar na percepção da equipe multidisciplinar}

$\mathrm{Na}$ abordagem com a equipe multidisciplinar, um estudo apresentou que o engajamento do enfermeiro na promoção da atividade de brincar, visando ao estabelecimento e ao estreitamento do vínculo, favorece a realização dos cuidados. ${ }^{(13)}$ Em outro estudo, os profissionais de saúde que atuam no cenário hospitalar precisam desenvolver habilidades para serem facilitadores e promotores da brincadeira no ambiente hospitalar. ${ }^{(2)}$

Uma revisão de literatura apontou os benefícios do brincar para a recuperação da criança hospitalizada, assim como para seus familiares e a equipe de saúde, que presta assistência e propicia um cuidado humanizado voltado não somente para a técnica durante a assistência e a realização de procedimentos. ${ }^{(15)}$

Por meio das brincadeiras, o profissional tem a oportunidade de entrar no mundo da criança, compreender as suas necessidades, emoções, medos e dúvidas, conseguindo, assim, intervir de maneira única, singular e direcionada a cada criança. ${ }^{(8)}$ Além de ser uma ferramenta que facilita a comunicação do profissional com a criança e da criança com o profissional, desde a simulação de um procedimento até a manifestação de seus sentimentos e vivências, o brinquedo permite a criação e o estreitamento do vínculo entre o profissional, a criança e sua família. ${ }^{(8)}$

Entretanto, reconhece-se que, para tornar a prática do BT efetiva nas unidades de internamento pediátricas, faz-se necessária a sensibilização dos órgãos gestores, para que eles promovam uma reorganização do processo de trabalho de enfermagem, assim como forneçam recursos materiais para concretizá-la, propiciando ainda capacitação permanente para os profissionais atuantes nas unidades de pediatria. ${ }^{(6)}$ Outro estudo reforça que o aprendizado sobre o brincar da criança necessita muito mais do que um ambiente com materiais e brinquedos. Faz-se necessário também resgatar dos profissionais uma visão de cuidar que compreenda o outro como a si mesmo, de maneira empática e sensível. ${ }^{(15)}$
Como limitação de pesquisa, destaca-se que alguns artigos foram excluídos da amostra por não estarem disponíveis gratuitamente na íntegra. Além disso, como o termo "briquedo terapêutico" não é um descritor/MeSH, isso pode ter limitado a busca.

Este estudo corroborou a literatura existente ao reforçar que o brincar e o BT são ferramentas promotoras do cuidado às crianças, além de facilitarem a comunicação entre a equipe de enfermagem, a criança e a família, promover a criação de laços e vínculos entre esses autores, trazer resultados positivos para a hospitalização da criança e apoiar o cuidado profissional.

\section{Conclusão}

Considera-se que o objetivo proposto foi atingido ao identificar, na literatura científica, estudos que apresentaram o impacto do uso do BT e o brincar na unidade pediátrica. Essas ferramentas apresentaram-se como maneiras de humanização e melhoria da assistência às crianças. A aplicação do BT durante a internação e a realização de procedimentos se mostrou benéfica para as crianças, pais e demais familiares e profissionais da equipe de saúde, sendo possível identificar uma melhora na humanização, nas respostas apresentadas pelas crianças e na perspectiva dos profissionais de saúde.

\section{Referências}

1. Fontes C, Oliveira AS, Toso LA. Therapeutic toy in pediatric intensive therapy unit. Rev Enferm UFPE online. 2017;11(Supl 7):2907-15.

2. Tolocka RE, Corrêa RE, Lima MM, Colombo CE, Poletto JE. Brincar e criança com câncer: que relação é essa? Licere (online). 2019;22(1):421-44.

3. Carvalho e Souza L, De Vitta A, Lima JM, De Vitta FC. The act of playing within the hospital context in the vision of the accompanying persons of the hospitalised children. J Hum Growth Dev. 2015;25(1):41-9.

4. Silva SR, Santos MC, Silva AM, Ferreira FA, Freitas RS, Gouveia MT, et al. Perception of the hospitalized child's companion in relation to therapeutic toys. Rev Enferm UFPE online. 2018;12(10):2703-9.

5. Fioreti FC, Manzo BF, Regino AE. The play therapy and child hospitalized in perspective of parents. Rev Min Enferm. 2016;20:e974.

6. Lemos IC, Oliveira JD, Gomes EB, Silva KV, Silva PK, Fernandes GP. Brinquedo terapêutico no procedimento de punção venosa: estratégia para reduzir alterações comportamentais. Rev Cuid. 2016;7(1):1163-70.

7. Rockembach JA, Espinosa TA, Cegano D, Soares DC. Inserção do lúdico como facilitador da hospitalização na infância: percepção dos pais. J Nurs Health. 2017;7(2):117-26.

8. Moreira PL, Silva IP. Utilização do brinquedo durante 0 tratamento de crianças com câncer: percepção da equipe multidisciplinar. Rev Bras Cancerol. 2018;64(3):311-8.

9. Sposito AM, Garcia-Schinzari NR, Mitre RM, Pfeifer LI, Lima RA, Nascimento LC. The best of hospitalization: contributions of playing to cope with chemotherapy. Av Enferm. 2018;36(3):328-37. 
0 brinquedo terapêutico e o impacto na hospitalização da criança: revisão de escopo

10. Arksey H, O'Malley L. Scoping studies: towards a methodological framework. Int J Soc Res Methodology. 2005;8(1):19-32.

11. Peters MD, Godfrey C, McInerney P, Munn Z, Tricco AC, Khalil, H. Capítulo 11: Revisões do escopo (versão 2020). In: Aromataris E, Munn Z (Eds.). JBI Manual for Evidence Synthesis. JBI; 2020.

12. Silva D0, Gama D0, Pereira RB, Camarão YP. The importance of play in the context of child hospitalization. Rev Enferm UFPE online. 2018;12(12):3484-91.
13. Depianti JR, Melo LL, Ribeiro CA. Playing to continue being a child and freeing itself from the confinement of the hospitalization under precaution. Esc Anna Nery. 2018;22(2):e20170313.

14. Alcântara PL, Wogel AZ, Rossi MIL, Neves IR, Sabates AL, Puggina AC. Effect of interaction with clowns on vital signs and non-verbal communication of hospitalized children. Rev Paul Pediatr. 2016;34(4):432-8.

15. Alves JF, Lima MD, Mendonça RR, Camargos MC, Silva KR. Play Promotion: Strategic Management in Action Combat Child Hospitalization. Gerais Rev Saúde Pública SUS/MG. 2016;4(1)89-100. 